DOI: 10.1136/annrheumdis-2017-eular.5352

\section{AB1083 WORK IMPAIRMENT IN PATIENTS EXPERIENCING MUSCULOSKELETAL PAIN}

N.M. Higgins ${ }^{1}$, A. Cochrane ${ }^{1}$, C.J. Rothwell ${ }^{1}$, O. FitzGerald ${ }^{2}$, P. Gallagher ${ }^{3}$, J. Ashton ${ }^{4}$, R. Breen ${ }^{5}$, A. Brennan ${ }^{6}$, O. Corcoran ${ }^{7}$, D. Desmond ${ }^{1}$. ${ }^{1}$ Department of Psychology, Maynooth University, Maynooth; ${ }^{2}$ School of Medicine and Medical Sciences, University College Dublin; ${ }^{3}$ School of Nursing and Human Sciences, Dublin City University; ${ }^{4}$ Physiotherapy Services, Beaumont Hospital; ${ }^{5}$ Royal College of Physicians in Ireland; ${ }^{6}$ Physiotherapy Services, AMNCH, Dublin; ${ }^{7}$ Rheumatology Services, Waterford University Hospital, Waterford, Ireland

Background: Many individuals with musculoskeletal disorders (MSD) continue to work. Little is known about those who remain occupationally active relative to those who are on sick leave, despite the clear potential for reduced productivity or work ability, and associated downstream effects.

Objectives: To assess self-reported work impairment and its associations with psychosocial risk factors amongst workers seeking care for musculoskeletal pain. Methods: Recruitment took place in five Irish hospitals. Self-report questionnaires were used to assess risk of progressing to long-term sick leave and work disability (Örebro Musculoskeletal Pain Screening Questionnaire; ÖMPSQ), work ability, work impairment (WPAI) and work performance (WRFQ).

Results: 155 patients (53.5\% female; mean age $=46.50$ years (range 20 to 71 )) completed the questionnaire. $25.2 \%(n=39)$ were at high risk of progressing to long-term sick leave and work disability according to the ÖMPSQ. 62.6\% $(n=97)$ were classified as functioning poorly according to the WRFQ; $52.3 \%$ reported having poor work ability $(n=81)$. Higher work role functioning was associated with higher pain self-efficacy $(O R=1.514)$; better work ability was associated with older age (OR $=1.063$ ) and poorer function ( $O R=0.929)$; absenteeism was associated with lower pain self-efficacy $(\mathrm{OR}=0.650)$ and higher return to work expectancy $(\mathrm{OR}=1.179)$. Presenteeism was associated with higher pain intensity $(\beta=0.259)$ and lower pain self-efficacy $(\beta=-0.385)$.

Conclusions: MSDs affect many individuals ability to work effectively. While all participants have managed to stay at work despite decreased levels of work ability and functioning, approximately a quarter are at high risk of progressing to long-term sickness absence. Interventions that attempt to improve mutable factors, such as pain self-efficacy, may help reduce the likelihood of work disability. Acknowledgements: This research is funded by the Health Research Board [RCQPS-2014-2].

Disclosure of Interest: None declared

DOI: 10.1136/annrheumdis-2017-eular.5981

\section{AB1084 CONTRIBUTION OF CLINICAL TRIALS TO THE EFFICIENCY OF ARTHRITIS RHEUMATOID MANAGEMENT}

C. Alcañiz Escandell, E. Vicens Bernabeu, F.M. Ortiz-Sanjuan, J.E. Oller Rodriguez, C. Nájera Herranz, I. Cánovas Olmos, E. Grau Garcia, C.M. Feced Olmos, E. Labrador Sánchez, K. Arévalo Ruales, R. Negueroles Albuixech, J. Ivorra Cortes, J.J. Fragio Gil, I. Martínez Cordellat, R. González Mazarío, I. Chalmeta Verdejo, L. Gonzalez Puig, J.A. Román Ivorra. Rheumatology Department, HUP la Fe, Valencia, Spain

Background: Treatment and management of Rheumatoid Arthritis (RA) results in a high cost to the Health system such as the Spanish Health System. During the realization of clinical trials (CT) the sponsor is the one that pays for the direct healthcare costs of the patients, which leads to savings to the National Health System (NHS).

Objectives: To estimate the economic impact of conducting clinical trials (CT) for the NHS in terms of avoided costs.

Methods: A retrospective observational study was conducted using information from the clinical trials performed at the Clinical Research Rheumatology Department in the HUP la Fe from 2011 to 2015. Also a Cost-analysis was performed according Health System perspective. We calculated the length of stay in the CT in weeks for each patient included with RA diagnosis. Afterwards, we also calculated the total number of weeks of treatment for the total number of patients. In order to evaluate the economic impact in terms of avoided costs, economic evaluation included direct healthcare costs (rheumatologist visits, nurse care, laboratory tests and pharmacological treatment), and it was compared to the cost of the best alternative treatment in the market.

Results: A total of 35 CT were analyzed in this period, 14 of them focused on RA. Two observational studies and one CT (premature closure by the sponsor) were discarded. Therefore, 11 were considered in this study and a total of 76 patients with RA were analysed which add together 2609 weeks of treatment. This is approximately equivalent to treating 50 RA patients with biological therapy during one year. Evaluating the health savings that biological treatment would have cost during the 2609 weeks, we obtain a total amount of $699.176,88 €$. This represents an annual saving of $139.835 €$ over the 5 years analyzed.

Conclusions: Our Clinical Research Unit managed to save a total amount of $13.935,30 €$ per patient in CT per year. Clinical Research Units should be considered as an efficient tool to the NHS.

Disclosure of Interest: None declared

DOI: 10.1136/annrheumdis-2017-eular.6082

\section{AB1085 MEASURING PATIENT SATISFACTION OF BIOLOGICAL TREATMENTS IN A REGIONAL HOSPITAL}

D. Grados ${ }^{1}$, A. Retamero ${ }^{2}$, A. Riveros ${ }^{1}$, C. Baliu ${ }^{3}$, E. Nogues ${ }^{3}$, D. Ferrandez ${ }^{2}$, F. Bové ${ }^{4}$, A.M. Colquechambi ${ }^{5}$, M. Cucurell ${ }^{3}$. ${ }^{1}$ Rheumatology; ${ }^{2}$ Pharmacy; ${ }^{3}$ Dermatology; ${ }^{4}$ Nursery; ${ }^{5}$ Family medicine, Hospital d'lgualada (consorci sanitari Anoia), Igualada, Spain

Objectives: To determine/measure the satisfaction degree of patients with rheumatologic (rheumatoid arthritis, spondyloarthropathies and other arthritis) and dermatological (psoriasis, psoriatic arthritis and suppurative hidrosadenitis) disease treated with a biological drug.

Methods: Descriptive prospective study conducted in a Regional Hospital with a reference area of 109,530 inhabitants.

A survey was conducted to all patients, thepatientswhocollectedtheir medication at the Pharmacy Service (self-administration treatment) and the patients who came for consultation (treatment administered by the nursing staff). The satisfaction degree before and after the biological treatmentwas evaluated.From 0 to 10 , where 0 was the maximum dissatisfaction and 10 the maximum satisfaction; and improvement of pain, where 0 implied no improvement and 10 maximum improvement.

Clinical records were reviewed and a database was generated for exploitation with SPSS-vs 22. All patients received an information sheet from the study and signed an informed consent form.

Results: A total of 100 patients were analyzed: 45 men and 55 women. The mean age was 53 years (SD 14.9). $42 \%$ of patients were actively employed.

Distribution of patients by pathologies: 46 (46\%) rheumatoid arthritis, $25(25 \%)$ psoriasis, $16(16 \%)$ psoriatic arthritis, $8(8 \%)$ spondyloarthropathies, $2(2 \%)$ suppurative hydrosadenitis and $1(1 \%)$ juvenile idiopathic arthritis.

Distribution of biological drugs: $49(49 \%)$ adalimumab, 20 (20\%) ustekinumab, 18 $(18 \%)$ etanercept, $6(6 \%)$ golimumab, $3(3 \%)$ tocilizumab, $2(2 \%)$ secukinumab, 1 $(1 \%)$ certolizumab. The treatment was self-administered in 61 patients.

Only $30(30 \%)$ patients had undergone previous biological treatment. At present, 43 patients had some additional treatment, 38 with methotrexate and 5 with leflunomide.

Satisfaction degree before biological treatment, $n(D E)$

Satisfaction degree after biological treatment, $n(S D)$

Pain improvement, $\mathrm{n}(\mathrm{SD})$

Comfort with the route of administration, $n$

Comfort with frequency of administration, $n$

Degree of pain during administration, $n(S D)$

Patients who have missed doses, $n$

Patients who have controlled the disease with the biological treatment, $n$

Patients who have improved the quality of life with the biological treatment, $n$

The patient considers to have sufficient information of the drug, $n$

The patient considers to have sufficient information of the disease, $n$

They belong to a patient association, $n$

$2.8(2.6)$

$7.9(1.6)$

$7.8(2.1)$

94

$3.2(3.2)$

15

93

93

80

Conclusions: The satisfaction degree of patients with their biological treatment is very high regardless of the route of administration. Most of them are in monotherapy or with low doses of FAME. $61 \%$ of patients self-administer the drug at home. $93 \%$ of patients consider that there has been a change in their quality of life and that they can lead a normal life.

Disclosure of Interest: None declared

DOI: 10.1136/annrheumdis-2017-eular.5483

\section{AB1086 THE PREVALENCE AND THE REACTIVATION RATES OF HEPATITIS IN PATIENTS WHO ARE TAKING AN IMMUNESUPRESSIVE AGENT FOR TREATMENT OF A RHEUMATOLOGICAL DISEASE}

B.N. Coskun ${ }^{1}$, B. Yagız ${ }^{1}$, S. Ermurat ${ }^{1}$, E.S. Danaci ${ }^{2}$, A.N. Tufan ${ }^{1}$, E. Dalkilic ${ }^{1}$. ${ }^{1}$ Rheumatology; ${ }^{2}$ Internal Medicine, Uludag University, Bursa, Turkey

Background: Today, the immunosuppressive treatment agents became important for therapy of rheumatoid diseases. Theoretically, the use of these agents may result in reactivations be in patients that infected with Hepatitis B (HBV) and Hepatitis $\mathrm{C}(\mathrm{HCV})$ virus.

Objectives: We aimed to study the reactions during treatment and prevalence of HBV and HCV infections in rheumatology patients who are using immunosuppressive treatment.

Methods: The records of a total of 1146 patients who were taking an immunosuppressive treatment for a rheumatoid disease were reviewed retrospectively. The hepatitis serology, type of immunosuppressive treatment, the duration of treatment, liver function tests, complete blood count; HBV - DNA and HCV - DNA and antiviral agents and time of use (if patient is infected) were recorded.

Results: There were 682 (59.5\%) women and 464 (40.5\%) men, the mean age was $45.04 \pm 13.13$. Ankylosing spondylitis (AS) was diagnosed in 453 , rheumatoid arthritis (RA) in 365, psoriatic arthritis in 151, systemic lupus erythematosus in 43 , vasculitis in 39 , Behçet Disease in 26 , systematic sclerosis in 18 , myositis in 9, juvenile rheumatoid arthritis in 7, Sjögren Syndrome in 7, Still Disease in 3, familial mediterian fever in 6 , retroperitoneal fibrosis in 1 and mixed connective tissue disease in 1 patient. The rate of $\mathrm{HbsAg}$ positivity was $1.8 \%$ in AS and $2.2 \%$ in RA; the rate of HCV positivity was $0.7 \%$ and $1.9 \%$ respectively. While 